\title{
Caracterização de um compósito polimérico biodegradável utilizando Poli ( $\varepsilon$-caprolactona) e borra de café
}

\section{Characterization of composite polymeric biodegradable using Poly (E-caprolactone) and coffee grounds}

\author{
Lúcia Helena Mei e Natália Oliveira ${ }^{1 *}$
}

\author{
1 Laboratório de Processamento de Polímeros, Departamento de Engenharia de Materiais e de \\ Bioprocessos, Faculdade de Engenharia Química, Universidade Estadual de Campinas - UNICAMP, \\ Campinas, SP, Brasil \\ *natalia.brisolla@yahoo.com.br
}

\begin{abstract}
Resumo
Este trabalho teve por objetivo avaliar a influência do tratamento químico da borra de café em relação as propriedades mecânicas e térmicas, morfologia e suscetibilidade à biodegradação quando utilizada na preparação de compósitos com Poli(E-caprolactona) comparando-o com o polímero puro. A borra de café foi submetida ao tratamento álcali com hidróxido de sódio, seguida da acetilação. Os compósitos foram preparados utilizando diferentes porcentagens de borra de café. Com tratamento químico houve um aumento na estabilidade térmica da borra de café. Houve um aumento significativo no módulo elástico para o compósito com $10 \%$ de borra de café acetilada. As imagens obtidas por MEV mostraram uma parcial interação fibra/matriz para compósitos com borra acetilada. As análises térmicas mostraram que a adição de borra de café deslocou positivamente $10^{\circ} \mathrm{C}$ o pico máximo de degradação térmica em relação ao polímero puro. As amostras mais suscetíveis à biodegradação foram as que continham borra de café acetilada.
\end{abstract}

Palavras-chave: compósito polimérico, borra de café, poliéster biodegradável.

\begin{abstract}
This study aimed to evaluate the influence of chemical treatments of coffee grounds in relation to mechanical, thermal and morphological properties, and its susceptibility to biodegradation when used in the preparation of composites with poly ( $\varepsilon$-caprolactone) as compared to pure polymer. The coffee grounds were submitted to alkali treatment with sodium hydroxide followed by acetylation. The composites were prepared using different percentages of coffee grounds. There was an increase in the thermal stability of coffee grounds using chemical treatment, and a significant increase of the elastic modulus for the composite with $10 \%$ acetylated coffee grounds. The images obtained by SEM showed a partial interaction between fiber/matrix for composites and acetylated coffee grounds. The Thermal analysis showed that the addition of coffee grounds positively shifted $10^{\circ} \mathrm{C}$, the maximum peak of thermal degradation, as compared to pure polymer. The most susceptible samples to biodegradation were those that contained acetylated coffee grounds.
\end{abstract}

Keywords: polymeric composite, coffee grounds, biodegradable polyester.

\section{Introdução}

Atualmente observa-se um grande aumento na utilização de embalagens plásticas em vários setores industriais. Porém, todo este plástico, após ser utilizado, é destinado aos aterros sanitários ou lixões a céu aberto. Geralmente estes materiais são derivados de fonte não renovável, como o petróleo, podendo levar mais de séculos até se decomporem totalmente na natureza. Para amenizar esta situação, recorre-se a reciclagem de alguns plásticos após triagem da coleta seletiva que alguns municípios praticam, porém não é possível garantir sua eficácia, pois, dependeria da conscientização da sociedade para que esta prática tivesse efeitos significativos. Por isso, muitas pesquisas estão voltadas para o desenvolvimento de biocompósitos poliméricos, com ênfase naqueles totalmente biodegradáveis feitos a partir de fibras naturais e polímeros biodegradáveis.

Os polímeros biodegradáveis sofrem degradação pela ação de microorganismos como bactérias, algas e fungos ${ }^{[1]}$ e podem ser divididos em quatro grupos: os polissacarídeos (alginato, pectina, amido e celulose); os poliésteres (Ex: polihidroxialcanoato); os polímeros sintetizados por monômeros obtidos de biomassa, como o poli (ácido lático); os poliésteres totalmente sintetizados por processos petroquímicos (Ex: Policaprolactona, $\mathrm{PCL})^{[2]}$.

O PCLé um polímero biodegradável sintético parcialmente cristalino, semirrígido à temperatura ambiente, com caráter hidrofóbico e uma baixa temperatura de transição vítrea. Este 
polímero vem sendo muito estudado por possuir vantagens como boas propriedades físicas e custo relativamente baixo, com relação a outros polímeros biodegradáveis, além de possuir uma boa miscibilidade com uma variedade de outros polímeros, pigmentos e cargas ${ }^{[3,4]}$.

As fibras naturais têm sido muito estudadas como reforço de muitos compósitos poliméricos, pois proporcionam diversas vantagens, tais como: a redução de custos do produto final; a baixa densidade; uma menor abrasão durante o processamento; são provenientes de fontes renováveis com grande disponibilidade; geram novas fontes de renda para a população rural; são biodegradáveis, o que reduz a quantidade de resíduos no meio ambiente ${ }^{[5]}$. Dentre as várias existentes pode-se citar as de juta, sisal, algodão, linho, fibra de palmeira, fibra de coco, fibras feitas de celulose regenerada e curauá.

As fibras naturais de origem vegetal ou lignocelulósicas são compostas basicamente de celulose, lignina e hemicelulose, de maneira que a celulose é o componente principal responsável pela estrutura da fibra. Sua unidade elementar é a anidro-d-glicose, cujos radicais hidroxilas (-OH) formam ligações de hidrogênio dentro e entre as moléculas de celulose, e com grupamentos hidroxila presentes na umidade do ar. Por isso todas as fibras lignocelulósicas são hidrofílicas, isto é, absorvem água numa faixa de 8 a $12,6 \%{ }^{[6]}$. Por tal razão, não há boa afinidade entre as fibras e a matriz e, por consequência, as propriedades mecânicas destas são afetadas. Para melhorar a adesão entre a fibra e a matriz, uma alternativa seria a modificação química da superfície da fibra.

A acetilação da fibra consiste na modificação química de sua superfície pela reação com anidrido acético, substituindo grupos hidroxilas por grupos acetila, cujo subproduto é o ácido acético. As fibras assim tratadas são menos hidrofílicas, permitindo maior aderência delas com a matriz polimérica ${ }^{[7]}$.

A borra de café é um passivo natural em aterros e, por ser constituída de celulose, lignina e hemicelulose pode ser explorada como material de reforço em compósitos poliméricos e, assim, ter um valor agregado a se considerar no futuro. Este material é descartado diariamente por residências e comércios em aterros sanitários em grandes quantidades, aumentando assim o passivo acumulado no lixo. Porém, se devidamente tratada, pode-se reaproveitá-la para se obter biocompósitos renováveis de custo bastante competitivo.

Deste modo, o objetivo principal deste trabalho é investigar a possibilidade de se obter um compósito polimérico totalmente biodegradável, utilizando-se a Poli ( $\varepsilon$-caprolactona) como matriz polimérica e borra de café como possível reforço que possa conferir boas propriedades aceitáveis à produção de alguns bens de consumo a preços competitivos.

\section{Materiais e Métodos}

Para a preparação dos compósitos foram utilizadas borra de café natural e acetilada, e um plastificante biodegradável de óleo de soja epoxidado (Resiflex K - 10) e Poli ( $\varepsilon$-caprolactona) (PCL - P-767) de massa molar $80.000 \mathrm{~g} / \mathrm{mol}$.
O óleo de soja epoxidado Resiflex K-10, utilizado como plastificante, foi fornecido pela Resypar Indústria e Comércio Ltda.

A acetilação foi realizada imergindo a borra de café em solução aquosa de $\mathrm{NaOH}$ ( $2 \%$ massa) e banho de gelo por 20 minutos, e lavada com água corrente até atingir $\mathrm{pH} 7$. A borra de café resultante foi seca em uma estufa na temperatura de $80^{\circ} \mathrm{C}$ por 24 horas. Posteriormente, foi colocada em um reator de vidro na presença de uma solução de 1,5:1 (v/v) de anidrido acético e ácido acético glacial, respectivamente. A reação ficou sob a agitação a uma temperatura de $120 \pm 5^{\circ} \mathrm{C}$, por um período de 2 horas. Terminada a reação, a borra de café foi retirada do reator por filtração a vácuo, e lavadas até a remoção total dos solventes. A seguir foi seca em uma estufa com circulação de ar na temperatura de $80^{\circ} \mathrm{C}$ por 24 horas. A armazenagem foi feita em um dessecador a vácuo ${ }^{[7-9]}$.

\subsection{Preparação dos compósitos}

Os compósitos de PCL/borra de café/Resiflex K-10 foram preparados, respectivamente, nas seguintes proporções em massa (m/m/m): 80:0:20, 75:5:20, 70:10:20 e 65:15:20, expressas em porcentagem.

Para cada formulação, foi utilizada uma massa total de 200 gramas de material. Os materiais foram misturados em um homogeneizador de alto cisalhamento da $\mathrm{MH}$ Equipamentos, modelo $\mathrm{MH}$ - 100, e em seguida colocados em uma prensa hidráulica também da $\mathrm{MH}$ Equipamentos, modelo $\mathrm{MH}-8-\mathrm{MT}$, regulada para $90^{\circ} \mathrm{C}$, com o objetivo de se obter filmes com espessura de 1,5 $\pm 0,5 \mathrm{~mm}$.

\subsection{Análise termogravimétrica da borra de café natural, acetilada e dos compósitos}

As fibras natural e acetilada e os compósitos foram analisados em uma termo-balança TGA, em atmosfera inerte de nitrogênio gasoso ultra seco, de grau cromatográfico, com vazão constante de $50 \mathrm{~cm}^{3} / \mathrm{min}$. As amostras foram previamente acondicionadas a $25^{\circ} \mathrm{C}$ e umidade relativa controlada de $50 \%$. As amostras pesadas, em torno de $11 \mathrm{~g}$, foram submetidas a uma programação de temperatura, com início na temperatura ambiente (aproximadamente $25^{\circ} \mathrm{C}$ ) e aquecida a uma taxa de $20^{\circ} \mathrm{C} / \mathrm{min}$, até atingirem a temperatura de $600{ }^{\circ} \mathrm{C}$.

\subsection{Análise de Espectroscopia no Infravermelho (FTIR) da borra de café natural e acetilada}

A borra de café foi analisada por espectroscopia no infravermelho, no Laboratório de Recursos Analítico e Calibração - LRAC da Faculdade de Engenharia Química UNICAMP, em um equipamento com transformada de Fourier, modelo Nicolet 6700, marca Thermo Scientific. Os espectros de infravermelho foram obtidos no modo ATR (Reflectância Total Atenuada) com acessório SMART OMNI-SAMPLER, na faixa de número de onda $4000-675 \mathrm{~cm}^{-1}$, com resolução de $4 \mathrm{~cm}^{-1}$ e 32 scan.

\subsection{Ensaio mecânico dos compósitos}

Os corpos de prova, processados na forma de filme prensado, foram confeccionados de acordo com a norma ASTM D-412. Para a realização dos ensaios mecânicos de 
tração foi utilizada uma Máquina Universal de Ensaios (MTS), modelo Alliance RT - 5, no Laboratório de Processamento de Polímeros da FEQ/UNICAMP, de acordo com a norma ASTM D-638. Neste ensaio foi utilizada uma célula de carga com capacidade de $1000 \mathrm{~N}$ e a velocidade de ensaio foi de $1 \mathrm{~mm} / \mathrm{min}$.

\subsection{Microscopia Eletrônica de Varredura (MEV)}

As análises de MEV foram realizadas no Laboratório de Recursos Analíticos e Calibração - LRAC, da Faculdade de Engenharia Química - UNICAMP. Para o recobrimento metálico das amostras utilizou-se um Sputter Coater POLARON, Modelo SC7620, da VG Microtech (Uckfield, Inglaterra). $\mathrm{O}$ cálculo para estimativa da espessura da camada de $\mathrm{Au}$ foi feito usando-se a expressão: Espessura $=$ K.i.V.t, onde $\mathrm{K}=0,17 \mathrm{~A} / \mathrm{mA}$.Volt.s; $\mathrm{i}=3 \mathrm{~mA} ; \mathrm{V}=1$ Volt e $\mathrm{t}=180 \mathrm{~s}$. Portanto, a espessura foi de $92 \mathrm{~A}^{\circ}$. Para obtenção das micrografias e/ou microanálise elementar foi utilizado um equipamento Microscópio Eletrônico de Varredura, com Detector de Energia Dispersiva de raios X, Modelo Leo 440i Modelo EDS: 6070, da LEO Electron Microscopy/Oxford (Cambridge, Inglaterra). Para as amostras utilizou-se tensão de aceleração igual a $15 \mathrm{kV}$ e corrente do feixe igual a $100 \mathrm{pA}$.

\subsection{Ensaio qualitativo de biodegradação dos compósitos}

Para verificar a influência da borra de café sobre o polímero, PCL, foi realizado um ensaio qualitativo para observar a biodegradabiliadede dos compósitos para as seguintes formulações: PCL plastificado e os compósitos de PCL puro (PCLp) com 10\% de borra de café natural e com $10 \%$ de borra de café acetilada.

Foi realizada uma simulação da disposição final ambientalmente correta para o compósito polimérico, ou seja, um aterro sanitário. Para preparar a terra em que o compósito foi aterrado, utilizou-se solo retirado próximo a uma horta. Neste solo foram adicionadas matéria orgânica (cascas de frutas) e água. Após uma semana, três amostras de cada formulação selecionada foram aterradas neste solo compactado ao máximo, pois, de acordo com a CETESB - Companhia de Tecnologia de Saneamento Ambiental do Estado de São Paulo ${ }^{[10]}$, um aterro sanitário tem por objetivo acomodar resíduos no menor espaço possível, ou seja, consiste em compactar o resíduo sólido em camadas que são cobertas por terra.

As amostras ficaram aterradas em solo, simulando um aterro sanitário, por 15, 30, 45, 60, 90 e 120 dias, sendo retiradas nos períodos citados para se obter imagens no microscópio óptico com o objetivo apenas de observar qualitativamente nas imagens se houve um ataque microbiano dos compósitos aterrados.

\subsection{Microscopia Óptica (MO) dos compósitos em biodegradação}

As imagens obtidas do PCLp e dos compósitos com 10\% de fibra natural, $10 \%$ de fibra silanizada e com $10 \%$ de fibra acetilada foram obtidas no Laboratório de Microbiologia do Hospital Público Jair Aparecido Olivotti, em Extrema - MG, marca Nikon, modelo ECLIPSE E200, seguindo os seguintes parâmetros de análise: amostra seca, luz incidente no campo claro e escuro, com utilização de lamínula e com um aumento da superfície do material em 40x e 100x.

\section{Resultados e Discussões}

\subsection{Espectroscopia no Infravermelho com Transformada de Fourier (FTIR)}

Para a análise dos resultado obtidos, os valores de absorbância foram normalizados, dividindo-os pelo valor da banda em $1051 \mathrm{~cm}^{-1}$, e depois, foram convertidos em transmitância, usando a equação $\mathrm{A}=-\log \mathrm{T}$.

De acordo com a Figura 1, registraram-se os espectros FT-IR para borra de café natural e acetilada.

$\mathrm{O}$ espectro no infravermelho mostra vários indícios de que ocorreu acetilação na borra de café. Uma das mais fortes evidências para a borra de café acetilada é a diminuição da intensidade da banda entre $3300-3500 \mathrm{~cm}^{-1}$, referente à vibração axial característica das hidroxilas $(\mathrm{OH})$, quando comparada ao espectro da natural. Entretanto, nota-se que a reação de acetilação foi incompleta, pois, ainda a banda persiste. Embora a esterificação do grupamento $\mathrm{OH}$ não tenha sido completa, ela já é potencialmente interessante, pois reduz sua higroscopicidade, diminuindo os sítios de $\mathrm{OH}$ que favorecem a absorção de água pela mesma ${ }^{[11]}$.

Outra prova de que a acetilação ocorreu é o aparecimento da banda entre $1735-1750 \mathrm{~cm}^{-1}$ correspondente à vibração do grupo carbonila $(\mathrm{C}=\mathrm{O})$ presente em ésteres. Pode-se observar que no espectro da borra de café natural também há o aparecimento de uma banda nesta região, esta presença se deve possivelmente a uma oxidação natural das mesmas ${ }^{[12]}$. A reação de esterificação pode ser confirmada também pelo aparecimento do pico $1162-1229 \mathrm{~cm}^{-1}$ na borra de café acetilada, que é atribuído ao estiramento $\mathrm{C}-\mathrm{O}$ de ésteres, e a banda em $1373 \mathrm{~cm}^{-1}$ referente ao estiramento $\mathrm{C}-\mathrm{H}$ do grupo acetila $^{[13]}$.

Finalmente, em $1645 \mathrm{~cm}^{-1}$ observa-se a deformação $\mathrm{H}-\mathrm{O}-\mathrm{H}$ de $\mathrm{H}_{2} \mathrm{O}$, demonstrando que a borra da café natural tem maior afinidade com a água do que a tratada ${ }^{[14]}$.

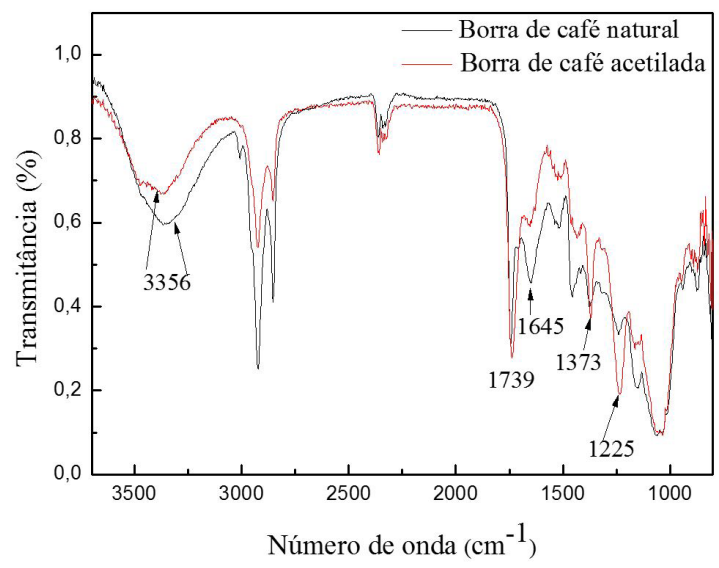

Figura 1. Espectro no Infravermelho das fibras de borra de café, natural e quimicamente tratada. 


\subsection{Análise Termogravimétrica (TGA) da borra de café}

Para verificar a estabilidade térmica da borra de café, antes e depois do tratamento químico, foram feitas duas TGAs, uma da borra in natura e outra da borra de café tratada. As curvas de perda de massa com a temperatura podem ser visualizadas na Figura 2.

Ao comparar as duas curvas observa-se que o comportamento foi diferente com o aquecimento. Inicialmente observa-se uma perda de massa para a borra de café não modificada, que se inicia antes e se estabiliza ao redor de $100{ }^{\circ} \mathrm{C}$. Essa perda geralmente é dada a compostos voláteis presentes na amostra, tais como moléculas de água, que evaporam nesta faixa de temperatura ${ }^{[8]}$. E por se tratar de um material hidrofílico, é possível que mesmo após a secagem a borra de café ainda tenha água presente alojada em seu interior. Isso é claramente evidenciado nos espectros de FT-IR, em que bandas de absorção de grupos - $\mathrm{OH}$ acima de $3000 \mathrm{~cm}^{-1}$ são observadas para amostras de borra de café natural (Figura 1).

Nota-se que a fibra natural começa a degradar em $225^{\circ} \mathrm{C}$ e a acetilada em $276^{\circ} \mathrm{C}$, portanto com um ganho significativo de estabilidade térmica próximo de $50^{\circ} \mathrm{C}$.

O comportamento analisado mostra que a borra de café acetilada possui maior estabilidade térmica, suportando maiores temperaturas de processamento sem degradar, comparada à natural. Tal resultado também foi observado na literatura corroborando nossos resultados ${ }^{[8,15,16]}$.

\subsection{Ensaio mecânico}

Os compósitos e a resina de policaprolactona plastificada (PCLp) foram submetidos ao ensaio de tração como mostra a Tabela 1.

Pelos resultados obtidos, nota-se um aumento significativo do Módulo Elástico (Tabela 1) dos materiais contendo borra de café até $10 \%$ acetilada ou não. A partir deste valor, ou seja, com $15 \%$ de borra de café natural, o módulo permaneceu com a mesma ordem de grandeza do valor obtido para PCL puro. Em outros estudos na literatura, esse comportamento também aparece e corrobora com nossos resultados ${ }^{[4,15]}$. Uma possível explicação para isso é que ao passar de determinados teores, nem todas as partículas foram molhadas pela matriz

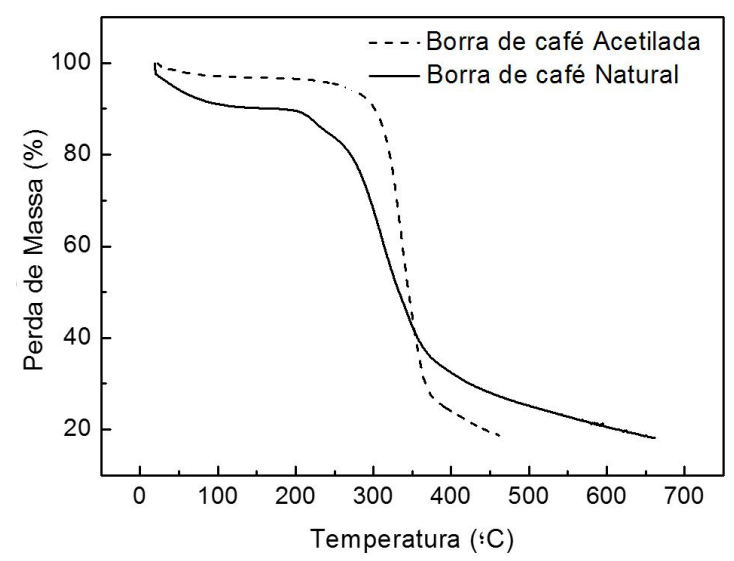

Figura 2. TGA da borra de café natural e acetilada previamente secas. no estado fundido e, assim, poderiam formar aglomerados de fibras pouco coesas. Ou ainda, cargas com maior rigidez do que as matrizes podem aumentar o módulo elástico do compósito ${ }^{[17]}$.

Para os resultados de Alongamento na Ruptura (Tabela 1), no geral, nota-se uma diminuição do valor à medida que 0 teor de borra de café aumenta na matriz, independente se as mesmas sofreram ou não o tratamento químico de acetilação. Nota-se também que em todos os casos a borra de café acetilada tem menor valor de alongamento de ruptura em relação à fibra não tratada, pois, quando ocorre um aumento do módulo elástico geralmente tem-se uma diminuição no alongamento de ruptura ${ }^{[17]}$.

Para os resultados de Resistência à tração (Tabela 1) observa-se uma diminuição dos valores para esta propriedade em relação ao aumento do teor de fibra, para todos os casos. Comparando compósitos com mesmo teor observa-se também que fibras acetiladas apresentaram menores valores de resistência à tração em relação às fibras naturais não tratadas.

Outros artigos encontrados na literatura ${ }^{[15-19]}$ mostraram resultados semelhantes de diminuição de resistência à tração em relação ao conteúdo de carga tratada e não tratada.

Estes resultados para a Resistência à tração indicam que a interação química na interface fibra-matriz não foi tão eficiente quanto o esperado para as fibras acetiladas, como confirmados pelas micrografias obtidas por corte criogênico dos compósitos como mostradas na Figura 2 .

A Figura 3 mostra que a borra de café está distribuída de forma não uniforme na matriz polimérica. Observa-se também nas micrografias a presença de pequenos espaços vazios entre a fibra e a matriz polimérica, indicando que a interação entre elas não foi tão eficiente quanto o esperado, (como já visto no ensaio de tração), porém na borra de café natural este efeito mostrou ser mais acentuado. Assim, ficou evidente que a acetilação da borra de café foi parcial, não atingindo a grau esperado para que ocorresse uma boa interação fibra-matriz.

Apenas os compósitos contendo 10\% de borra de café natural e acetilada foram submetidos a análise termogravimétrica e aterrados em solo para observação qualitativa do início do ataque microbiano do material. Esta escolha foi realizada a partir dos resultados apresentados para o ensaio mecânico e morfologia dos compósitos poliméricos biodegradáveis. Embora os resultados apresentados anteriormente de

Tabela 1. Ensaio Mecânico da policaprolactona sem fibra (PCLp), com fibra natural não tratada $(\mathrm{N})$ e com fibra acetilada (A), em várias proporções.

\begin{tabular}{crrr}
\hline Formulações & \multicolumn{1}{c}{$\begin{array}{c}\text { Módulo } \\
\text { Elástico } \\
\text { (MPa) }\end{array}$} & $\begin{array}{r}\text { Resistência à } \\
\text { tração }(\mathbf{M P a})\end{array}$ & $\begin{array}{c}\text { Alongamento } \\
\text { na Ruptura } \\
(\%)\end{array}$ \\
\hline PCLp & $97,64 \pm 10,04$ & $24,78 \pm 3,33$ & $158,82 \pm 11,54$ \\
$5 \% \mathrm{~N}$ & $153,31 \pm 16,40$ & $21,95 \pm 2,33$ & $142,42 \pm 9,36$ \\
$5 \% \mathrm{~A}$ & $149,53 \pm 5,30$ & $19,50 \pm 1,52$ & $127,26 \pm 5,38$ \\
$10 \% \mathrm{~N}$ & $125,46 \pm 12,43$ & $16,24 \pm 10,57$ & $117,49 \pm 6,59$ \\
$10 \% \mathrm{~A}$ & $158,73 \pm 4,27$ & $14,22 \pm 0,39$ & $106,41 \pm 4,19$ \\
$15 \% \mathrm{~N}$ & $99,43 \pm 6,34$ & $13,93 \pm 0,38$ & $108,71 \pm 3,45$ \\
$15 \% \mathrm{~A}$ & $153,88 \pm 13,02$ & $11,89 \pm 0,58$ & $96,37 \pm 5,27$ \\
\hline
\end{tabular}




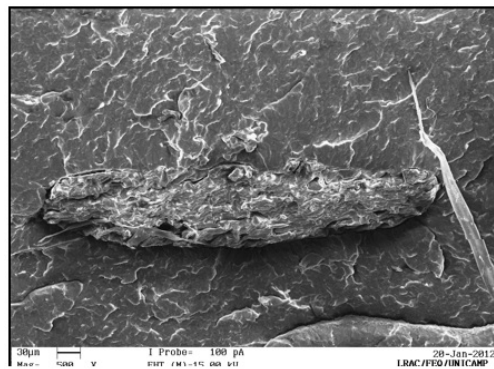

(a)

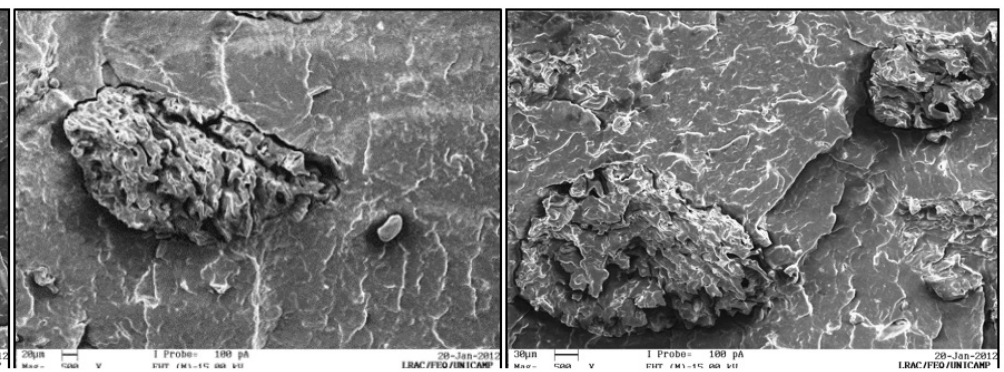

(b) (c)

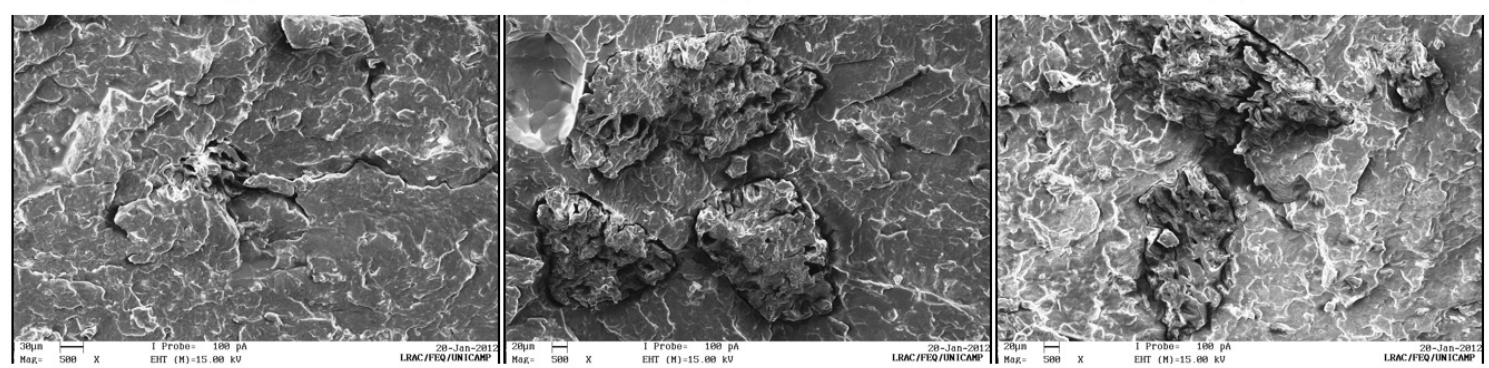

(d)

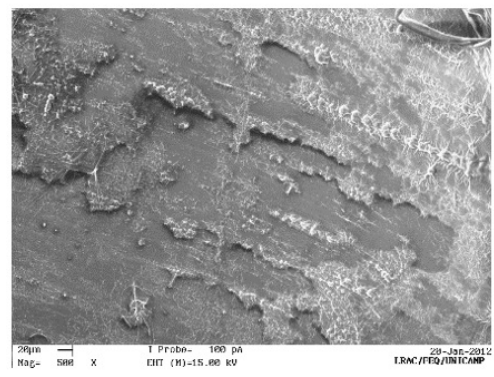

(g) (e)

(f)

Figura 3. Imagens obtidas por MEV aumentada 500x, para os compósitos de PCL com os seguintes teores de borra de café: (a) $5 \%$ A; (b) $5 \% \mathrm{~N}$; (c) $10 \% \mathrm{~A}$; (d) $10 \% \mathrm{~N}$; (e) $15 \% \mathrm{~A}$; (f) $15 \% \mathrm{~N}$; e micrografia da superfície do PCLp (g).

propriedades mecânicas para este compósito não tenham sido os melhores, a escolha também considerou o fator custo do material final, em que uma maior quantidade de carga pode baratear o custo do compósito.

\subsection{Análise termogravimétrica dos compósitos poliméricos}

A Figura 4 apresenta as curvas termogravimétricas para o PCLp e para os compósitos formulados com $10 \%$ de borra de café natural e acetilada, enquanto as Figuras 5-7 apresentam suas respectivas derivadas da variação de massa em relação à temperatura.

Percebe-se pelas curvas apresentadas na Figura 4 que a degradação térmica dos materiais analisados tiveram comportamentos muito parecidos evidenciando uma estabilidade térmica para o PCLp ligeiramente maior.

Na Figura 5a a curva de DTG do PCLp mostra dois estágios de degradação térmica, sendo o primeiro em $268{ }^{\circ} \mathrm{C}$, com $10 \%$ de perda de massa. Este pico pode ser associado ao início de degradação térmica do polímero devido à presença do plastificante, que neste caso tende a

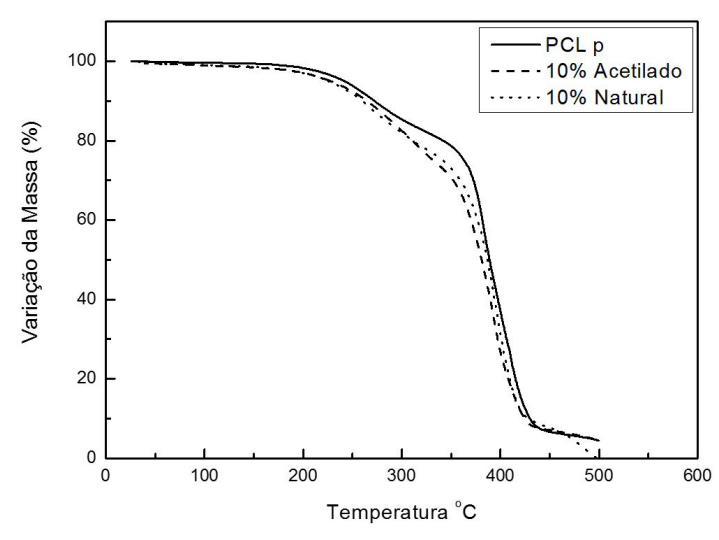

Figura 4. Análise termogravimétrica (TGA) para o PCLp e seus compósitos com $10 \%$ de borra de café acetilada e 10\% de borra de café natural.

diminuir a temperatura de degradação térmica do material. Este início de degradação térmica também foi observado na Figura $5 \mathrm{~b}$, com início de degradação térmica em $262^{\circ} \mathrm{C}$, e na Figura $5 \mathrm{c}$ com início de degradação térmica em $285^{\circ} \mathrm{C}$. 


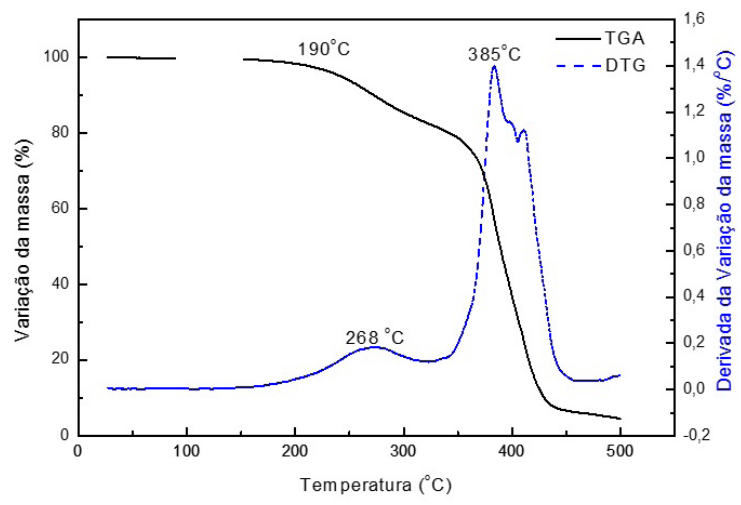

(a)

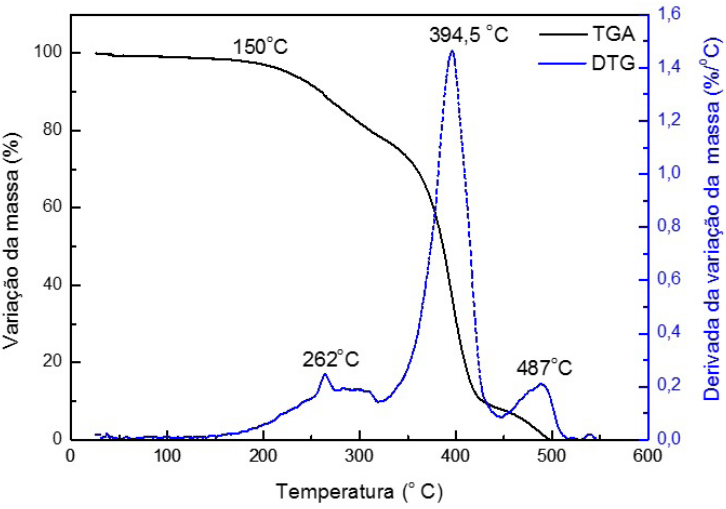

(b)

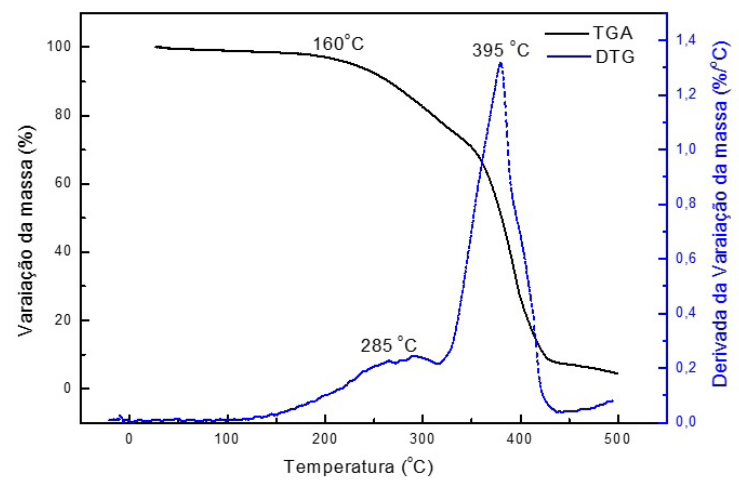

(c)

Figura 5. Termograma (TG) e Derivada (DTG) da variação da massa para (a) PCL plastificado; (b) compósito com 10\% de borra de café natural; (c) compósito com $10 \%$ de borra de café acetilada

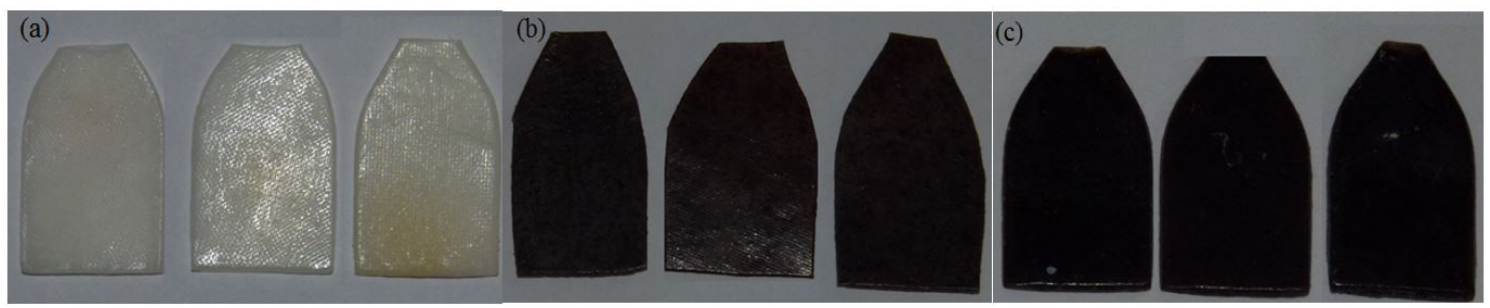

Figura 6. Imagens das amostras para a degradação em solo: (a) PCLp; (b) compósito com 10\% borra de café natural; (c) compósito com $10 \%$ de borra de café acetilada.

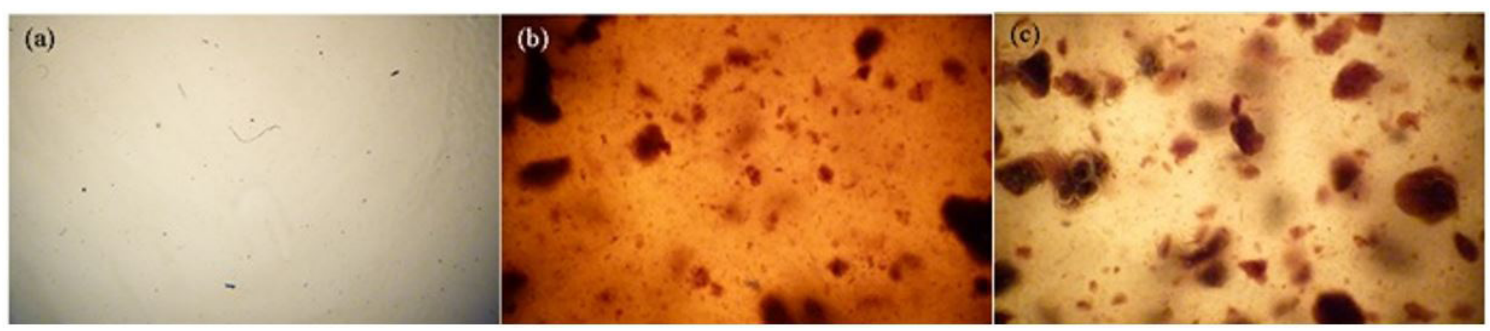

Figura 7. Imagens obtidas por microscopia óptica com aumento de 40x no início da degradação: (a) o PCLp e os compósitos com (b) $10 \%$ de fibra natural (c) $10 \%$ de fibra acetilada. 
Um segundo pico apareceu em $385^{\circ} \mathrm{C} 5$ (a) e sua presença também foi confirmada na literatura e pode ser atribuído a degradação térmica do PCL com início em $360^{\circ} \mathrm{C}$, com uma rápida perda de massa entre $383-444{ }^{\circ} \mathrm{C}^{[3]}$.

Na Figura 5 b observam-se três estágios de degradação: o primeiro em $262{ }^{\circ} \mathrm{C}$ com $10 \%$ de perda de massa pode estar associado à borra de café; o segundo, correspondendo a um pico máximo em $394,5^{\circ} \mathrm{C}$, refere-se à degradação do PCLp, que com a presença da borra de café, teve um ganho de $10^{\circ} \mathrm{C}$ em relação ao polímero plastificado puro. Por último, em $487^{\circ} \mathrm{C}$ pode-se atribuir à degradação da lignina que se decompõe em uma faixa entre 350 e $500{ }^{\circ} \mathrm{C}$, lembrando que este componente não aparece na Figura $5 \mathrm{c}$, pois foi remivido durante o tratamento químico de acetilação ${ }^{[20]}$. A Figura $5 \mathrm{c}$ referente ao compósito com $10 \%$ de borra de café acetilada, mostra dois estágios de degradação; o primeiro em $285{ }^{\circ} \mathrm{C}$ com $10 \%$ de perda de massa pode ser associado ao início de degradação da borra de café. O segundo em $395^{\circ} \mathrm{C}$, correspondente ao ponto máximo da degradação está associado à decomposição do compósito, que na presença da borra de café teve um aumento em $10^{\circ} \mathrm{C}$ quando comparado ao PCLp.

Ambos os compósitos com borra de café natural e acetilada apresentaram um aumento em $10^{\circ} \mathrm{C}$ para o pico máximo de degradação, quando comparados ao PCLp.

\subsection{Estudo qualitativo da biodegradação dos compósitos obtidos}

Antes que as amostras fossem submetidas à uma observação qualitativa do início de biodegradação, foram registradas suas imagens no microscópio óptico e câmera fotográfica para se ter um parâmetro inicial a ser seguido e assim compará-lo com as demais imagens.

$\mathrm{Na}$ Figura 7 pode-se observar que o compósito com borra de café acetilada (Figure 7c) apresentou uma coloração mais clara quando comparado à do compósito com borra natural, possivelmente o tratamento prévio da borra de café por mercerização, retirou parte da lignina tornando-o mais claro. Em relação ao PCLp (Figure 7a), verifica-se uma superfície com aparência homogênea.

As Figuras 8-10 mostram imagens obtidas no microscópio óptico e estão organizadas em ordem cronológica de degradação.

Pode-se observar na Figura 8 que com o passar do tempo o PCLp foi sofrendo mudanças em seu aspecto físico, podendo estas serem atribuídas possivelmente a um processo biodegradativo com o aparecimento de focos de desintegração como indicado pela seta na Figura 8d.

Ao adicionar borra de café ao polímero, observou-se que $\mathrm{o}$ ataque microbiano foi acelerado, conforme mostram

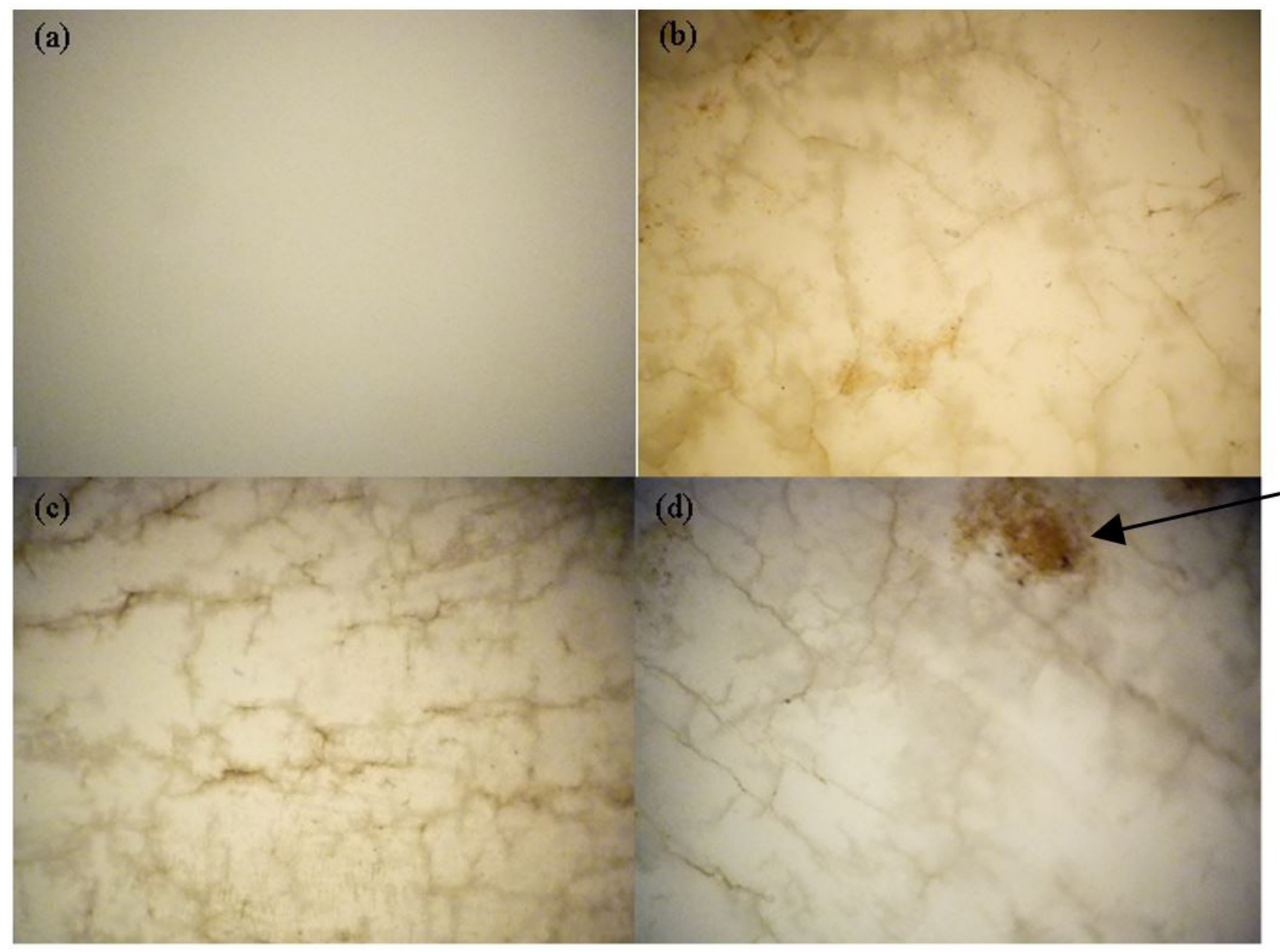

Figura 8. Imagens obtidas por microscopia óptica do PCLp, com aumento de 100x, após os seguintes dias de degradação: (a) 15; (b) 30; (c) 45 e (d) 60 . 


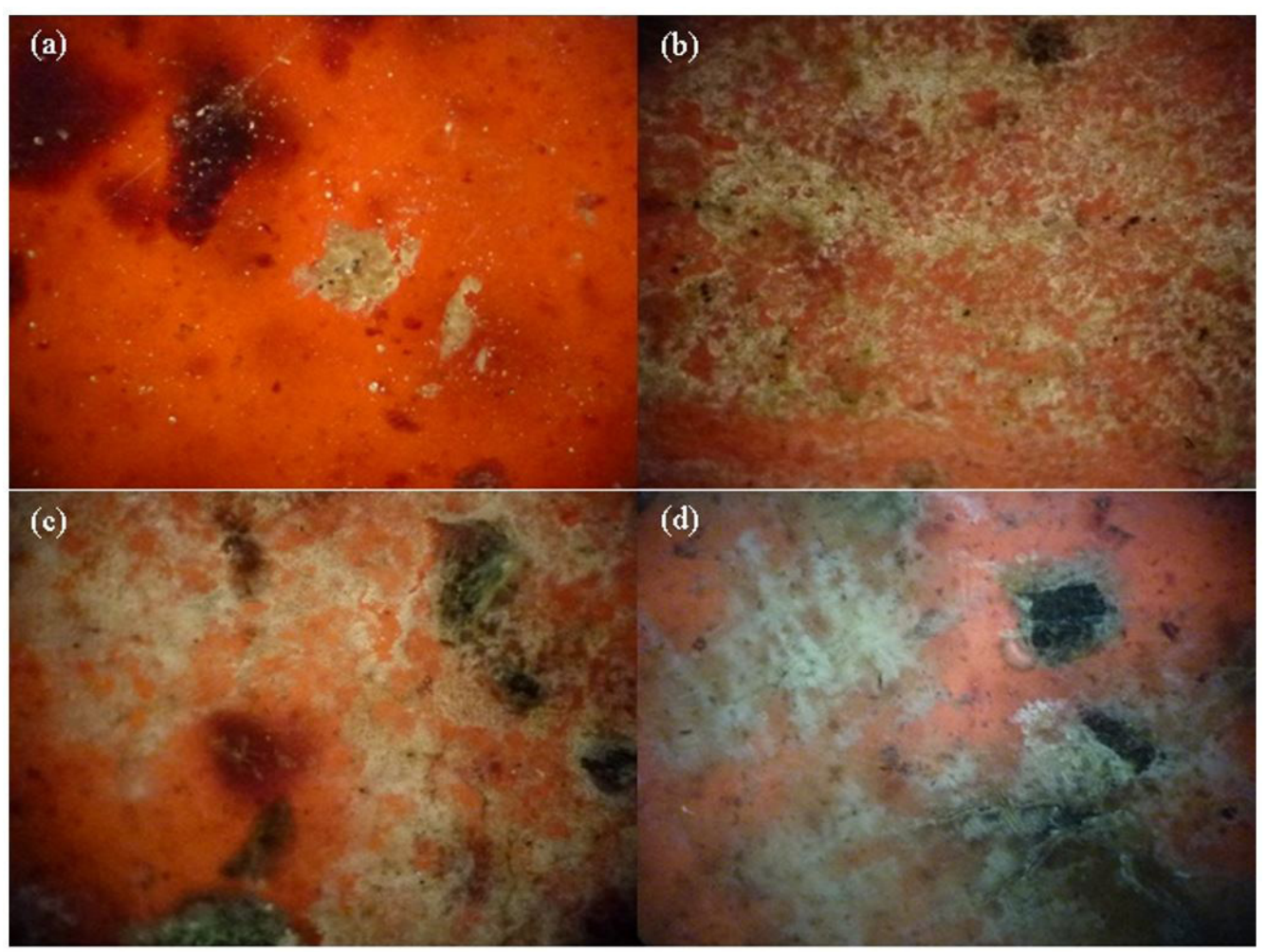

Figura 9. Imagens obtidas por microscopia óptica do compósito com $10 \%$ de borra de café natural, com aumento de 100x, após os seguintes dias de degradação: (a) 15 dias; (b) 30 dias; (c) 45 dias e (d) 60 dias.

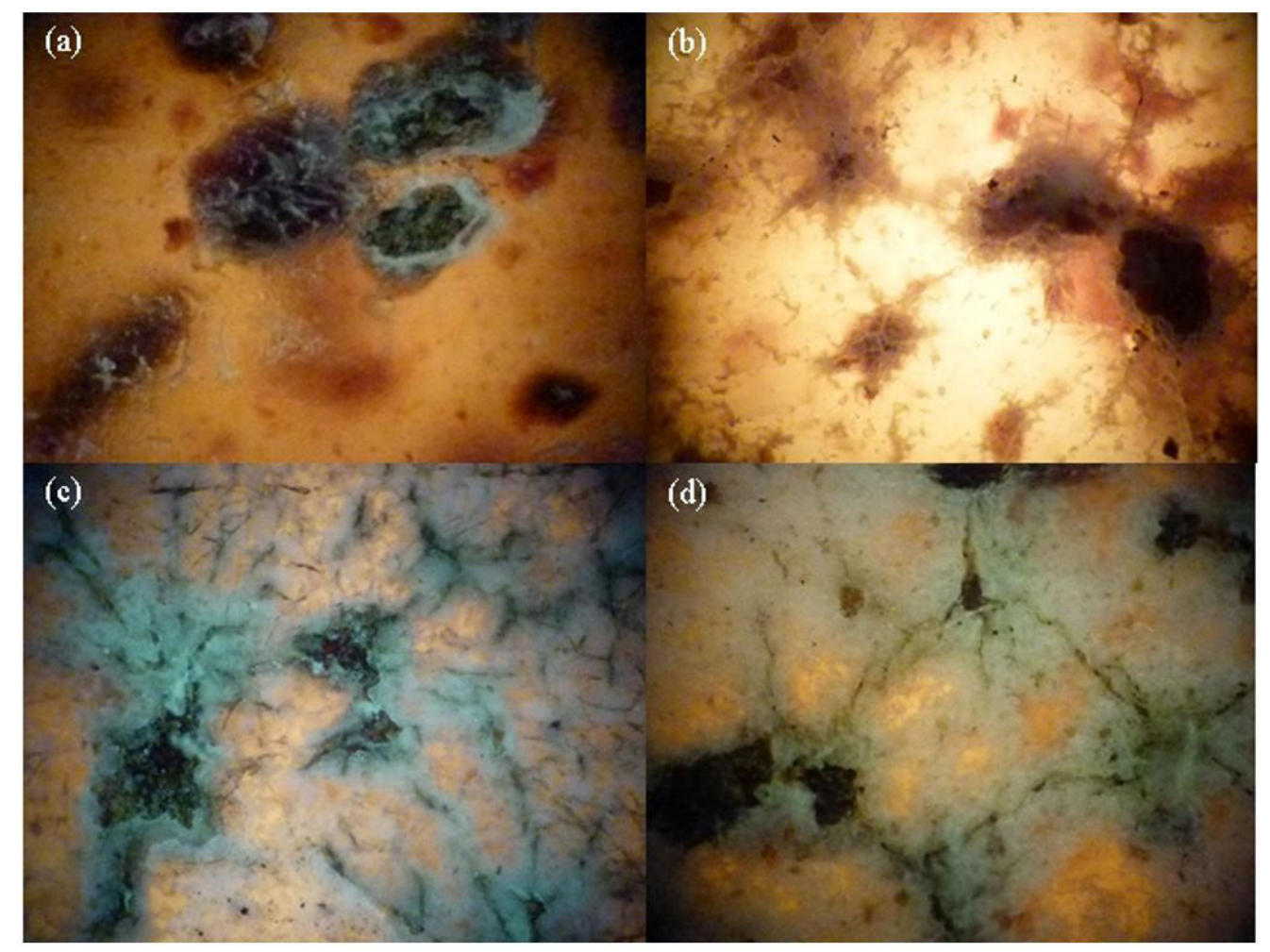

Figura 10. Imagens obtidas por microscopia óptica do compósito com $10 \%$ de borra de café acetilada, com aumento de 100x, após os seguintes dias de degradação: (a) 15 dias; (b) 30 dias; (c) 45 dias e (d) 60 dias. 
as Figuras 9a-d, 10a-d, para compósitos com borra natural e acetilada, respectivamente.

As imagens referentes à Figura 8 do PCLp mostraram que após quinze dias aterradas em solo o material não sofreu nenhuma alteração visível ao microscópio óptico. Porém, após trinta dias de incubação, o polímero sofreu pequenas alterações evidenciadas pela presença de pequenas fissuras na amostra. Tais fissuras possivelmente podem estar associadas à quebra hidrolítica das cadeias, característica da biodegradação de poliésteres, com consequente fragmentação e perda de integridade física. Apesar da imagem com 30 dias demonstrar um início de ataque do material por microrganismos, não houve grandes mudanças com o passar dos dias, quando se compara com as imagens de 45 e 60 dias de incubação no solo.

Para o compósito com $10 \%$ de borra de café natural (Figura 9), observa-se que após 15 dias houve o aparecimento de bolor produzido por fungos; com 30 dias há um maior ataque por parte dos fungos, e o aparecimento de fissuras e fungos na superfície do compósito é observada após 45 dias de permanência do material em solo.

Em relação à Figura 10, o compósito com 10\% de borra de café acetilada mostrou início de mudanças físicas com quinze dias de permanência em solo. É possível observar uma deterioração da amostra e formação de fissuras em torno da borra de café; após 30 dias, o ataque dos fungos e a presença de fissuras na superfície tornaram-se ainda mais intensas e nítidas (45 e 60 dias).

Comparando-se as três amostras, observa-se que a presença da borra de café pode ter acelerado o processo de ataque microbiano nas amostras. Em relação aos compósitos, os que são formados por borra de café tratada quimicamente mostraram-se mais suscetíveis ao ataque microbiano do que o compósito com borra de café natural. Uma possível explicação para a borra de café natural ter sido atacada por microorganismo mais lentamente (pela observação das imagens) que a acetilada, pode estar associado ao fato de que quando a borra de café foi mercerizada, houve a retirada da lignina. Como a lignina é um biopolímero que confere proteção à fibra natural contra o ataque microbiano, ou seja, sua presença impediu que os microorganismos atacassem o compósito em curto período de tempo ${ }^{[21]}$.

Como mostrado nas figuras anteriores, foi possível evidenciar um início de ataque microbiano dos materiais analisados. Nas Figuras 11-14 abaixo, foram registradas as imagens obtidas no microscópio óptico e câmera fotográfica para o PCLp e os compósitos com 10\% de borra de café natural e $10 \%$ acetilada em 90 e 120 dias, respectivamente, de biodegradação em solo. Essas imagens têm por objetivo mostrar uma estimativa de quão frágil e quebradiço eles se tornaram neste período de tempo.

Nas Figuras 11, 12 observa-se que o compósito com $10 \%$ de borra de café acetilada mostrou ser o mais suscetível ao ataque microbiano quando comparado com o compósito com $10 \%$ de borra de café natural, como mostrado pela seta na Figura 11c, em que há um foco de deterioração do compósito (aparecimento de um buraco).

Conclui-se então pela observação das imagnes que a adição de borra de café no material poderia acelerar o processo de degradação em solo, tornando assim a utilização deste compósito atrativo em termos de biodegradabilidade.

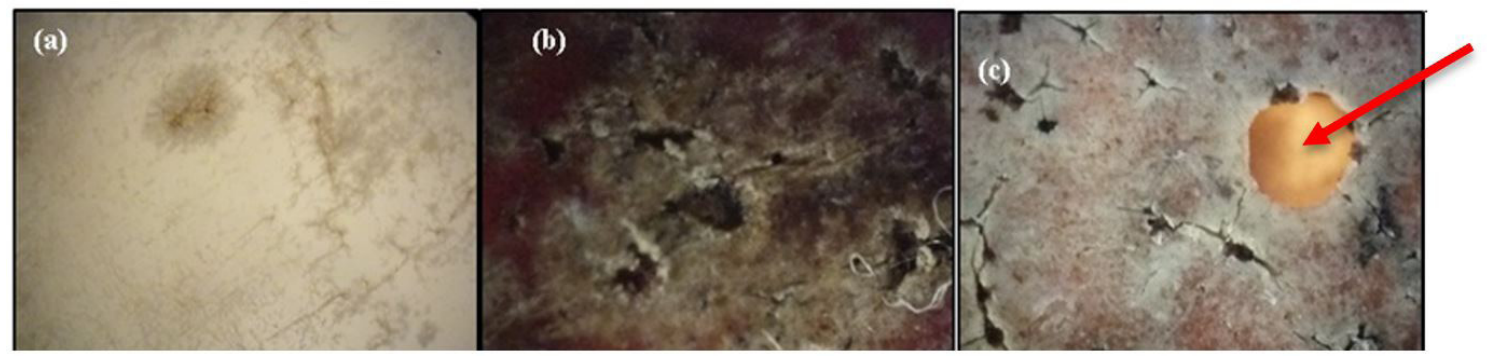

Figura 11. Imagens obtidas por microscopia óptica com aumento de 40x no campo escuro, após 90 dias de degradação para as amostras: (a) PCLp; (b) PCLp $/ 10 \%$ natural e (c) PCLp/10\% acetilada.
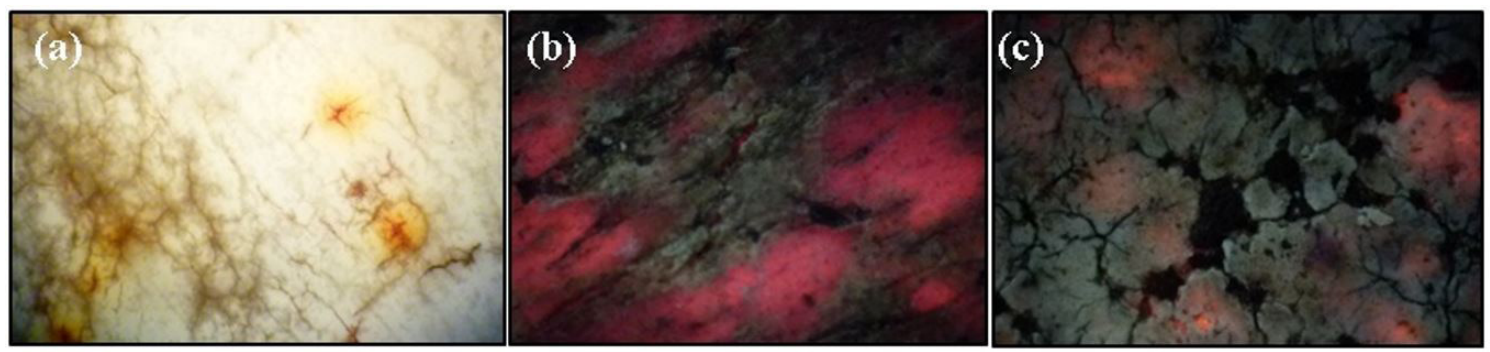

Figura 12. Imagens obtidas por microscopia óptica com aumento de 40x no campo escuro, após 120 dias de degradação para as amostras: (a) PCLp; (b) PCLp $/ 10 \%$ natural; (c) PCLp/10\% acetilada. 
2

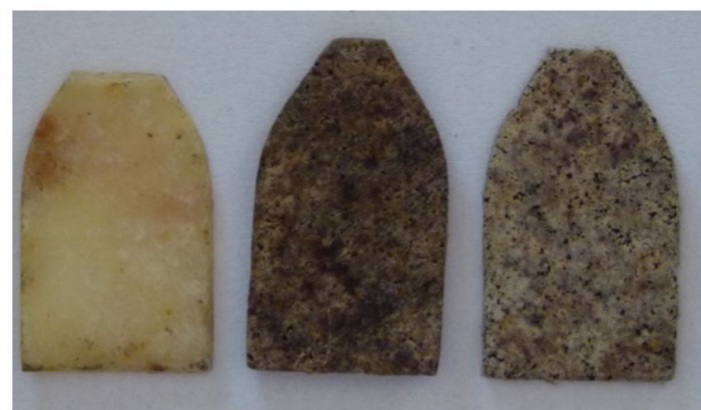

Figura 13. Imagens fotográficas obtidas após 90 dias de biodegradação em solo para o PCLp (1) e os compósitos com 10\% de fibra natural (2); 10\% de fibra acetilada (3).

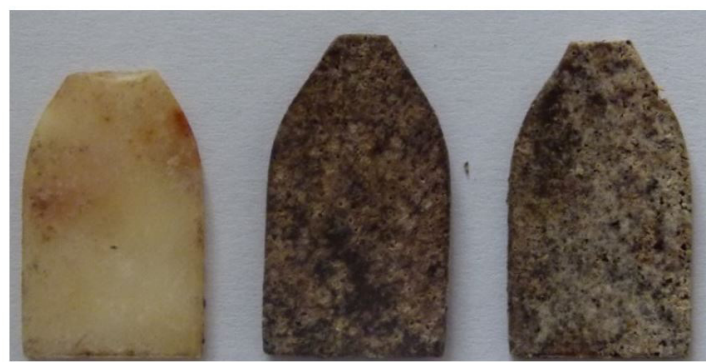

Figura 14. Imagens fotográficas obtidas após 120 dias de biodegradação em solo para o PCLp (1) e os compósitos com 10\% de fibra natural (2); $10 \%$ de fibra acetilada (3).

\section{Conclusões}

Conclui-se que a borra de café mostrou ser suscetível ao tratamento químico, como mostraram os resultados obtidos por FTIR, no qual grupos hidroxila foram parcialmente substituídos por acetila e a TGA mostrou que a borra de café acetilada teve um ganho na estabilidade térmica quando comparada a borra natural, e mostrou também uma aumento de $10^{\circ} \mathrm{C}$ para o pico máximo de degradação para o compósitos com com borra de café natural e acetilada quando comparado ao PCLp.

Em relação ao ensaio mecânico, houve um aumento significativo no valor do módulo elástico com a adição da borra de café tanto natural quanto para as quimicamente tratadas em relação ao PCLp, mostrando que os compósitos têm potencial para serem utilizados para materiais que requerem alta rigidez.

O ensaio qualitativo de biodegradação dos compósitos com $10 \%$ de borra de café mostrou que a presença tanto da natural quanto acetilada apresentaram-se mais suscetíveis ao processo de biodegradação do material, viabilizando a utilização do mesmo, quando a preocupação principal é obter um material dentro dos padrões sustentáveis atuais e com menor custo do produto final.

\section{Referências}

1. Ozaki, S. K. (2004). Compósitos biodegradáveis de resíduos de madeira-PVA modificado por anidrido ftálico (Tese de doutorado). Universidade de São Paulo, São Carlos.

2. Averous, L., \& Boquillon, N. B. (2004). Biocomposites based on plasticized starch: thermal and mechanical behaviours. Carbohydrate Polymers, 56(2), 111-122. http://dx.doi. org/10.1016/j.carbpol.2003.11.015.

3. Cordi, L. (2008). Estudo da biodegradação dos filmes de Poli (e-caprolactona), da blenda Poli (ecaprolactona)/amido e do compósito Poli (e-caprolactona)/amido/pó de fibra de coco por fungos e bactérias (Dissertação de mestrado). Universidade Estadual de Campinas, Campinas.

4. Mohanty, A. K., Misra, M., \& Hinrichsen, G. (2000). Biofibres, biodegradable polymer and composites: an overview. Macromolecular Materials and Engineering, 276-277(1), 1-24. http://dx.doi.org/10.1002/(SICI)14392054(20000301)276:1<1::AID-MAME1>3.0.CO;2-W.

5. Corradine, H., Agnelli, J. A. M., Morais, L.C., \& Mattoso, L. H. C. Estudo das Propriedades de compósitos biodegradáveis de amido/ glúten de milho/ glicerol reforçados com fibras de sisal. Polímeros: Ciência e Tecnologia, 18(2), 353-358. http:// dx.doi.org/10.1590/S0104-14282008000400016.

6. Santos, P. A.(2006). Uso de Fibra de Curauá como agente de reforço para Poliamida 6 (Dissertação de mestrado). Universidade Estadual de Campinas, Campinas.

7. Li, X., Tabil, L. G., \& Panigrahi, S. (2007). Chemical treatments of natural fiber use in natural fiber-reinforced composites: a review. Journal Polymer Environ, 15(1), 25-33. http://dx.doi. org/10.1007/s10924-006-0042-3.

8. Jesus, R. C. (2008). Processamento e caracterização de biocompósitos de PHB com fibras naturais de coco e sisal acetiladas e não-acetiladas (Dissertação de mestrado). Universidade Estadual de Campinas, Campinas.

9. Lopes, F. F. M., Araújo, G. T., Nascimento, J. W. B., Vasconcelos, R. F., \& Dantas, J. M. (2011). Avaliação dos efeitos da acetilação nas propriedades das fibras de caroá. Revista Brasileira de Engenharia Agrícola e Ambiental, 15(1), 84-89. http://dx.doi. org/10.1590/S1415-43662011000100012.

10. Companhia Ambiental do Estado de São Paulo. (2014). São Paulo: CETESB. Recuperado em 24 de agosto de 2014, de http://www.cetesb.sp.gov.br/mudancas-climaticas/biogas/ Aterro $\% 20$ Sanit $\% \mathrm{C} 3 \% \mathrm{~A} 1$ rio/21-Aterro $\% 20$ Sanit $\% \mathrm{C} 3 \% \mathrm{~A} 1$ rio

11. d'Almeida, A. L. F. S., Calado, V., \& Barreto, D. W. (2005). Acetilação da fibra de bucha (Luffa cylindrica). Polímeros: Ciência e Tecnologia, 15(1), 59-62. http://dx.doi.org/10.1590/ S0104-14282005000100013.

12. Tserki, V., Zafeiropoulos, N. E., Simon, F., \& Panayiotou, C. (2005). A study of the effect of acetylation and propionylation surface treatments on natural fibres. Composites Part A: Applied Science and Manufacturing, 36(8), 1110-1118. http://dx.doi. org/10.1016/j.compositesa.2005.01.004.

13. Lopes, F. F. M., Araújo, G. T., Nascimento, J. W. B., Gadelha, T. S., \& Silva, V. R. (2009). Estudo dos efeitos da acetilação em fibras de sisal. Revista Brasileira de Engenharia Agrícola e Ambiental, 14(7), 783-788. http://dx.doi.org/10.1590/S141543662010000700015.

14. Kandori, K., Yasukawa, A., \& Ishikawa, T. (1995). Preparation and characterization of spherical calcium hydroxy apatite. Chemistry of Materials, 7(1), 26-32. http://dx.doi.org/10.1021/ cm00049a007.

15. Sanchez, E. M. S., Cavani, C. S., Leal, C. V., \& Sanchez, C. G. (2010). Compósito de resina de poliéster insaturado com bagaço de cana de açúcar: influência do tratamento das fibras 
nas propriedades. Polímeros: Ciência e Tecnologia, 20(3), 194 200. http://dx.doi.org/10.1590/S0104-14282010005000034.

16. Pinheiros, I. F. (2012). Biocompósitos poliméricos de Poli(Butileno Adipato-Co-Tereftalato) - Pbat e fibra natural de Munguba, nativa da Amazônia (Pseudobombax munguba) (Dissertação de mestrado). Universidade Estadual de Campinas, Campinas.

17. Marcovich, N. E., Aranguren, M. I., \& Reboredo, M. M. (2001). Modified wood flour as thermo set fillers part I: effect of the chemical modification and percentage of filler on the mechanical properties. Polymer, 42(2), 825. http://dx.doi. org/10.1016/S0032-3861(00)00286-X.

18. Mothé, C. G., \& Araujo, C. R.(2004). Caracterização térmica e mecânica de compósitos de poliuretano com fibras de curauá. Polímeros: Ciência e Tecnologia, 14(4), 274-278. Recuperado em 24 de agosto de 2014, de http://www.scielo.br/pdf/po/ v14n4/22073.pdf
19. Joseph, K., Medeiros, E. S., \& Carvalho, L. H. (1999). Compósitos de matriz poliéster reforçados por fibras curtas de sisal. Polimeros: Ciência e Tecnologia, 9(4), 136-141. http:// dx.doi.org/10.1590/S0104-14281999000400023.

20. Santos, M. L., Lima, O. J., Nassar, E. J., Ciuffi, K. J., \& Calefi, C. F. (2011). Estudo das condições de estocagem do bagaço de cana-de-açúcar por Análise Térmica. Quimica Nova, 34(3), 507-511. http://dx.doi.org/10.1590/S0100-40422011000300024.

21. Salvi, M. B. (2011). Fungos basidiomicetos em biorremediação. São Paulo: Instituto de Botânica de São Paulo (IBt)/Programa de Pós Graduação em Biodeversidade Vegetal e Meio Ambiente.

Enviado: Ago. 21, 2015

Revisado: Maio 05, 2016

Aceito: Maio 26, 2016 